\title{
Direito Ambiental Constitucional: Uma Perspectiva Principiológica Normativista
}

\author{
Sérgio Braga Júnior* \\ Universidade Federal do Rio Grande do Norte, Departamento de Direito Público, Natal-RN, Brasil. \\ iD https://orcid.org/oooo-0oo1-8716-7468
}

\begin{abstract}
Resumo: O escopo deste artigo é, primordialmente, tratar da salvaguarda de direitos trazida à baila pela Constituição de 1988, relevantes à tutela de patrimônios naturais e paisagísticos. Busca-se promover uma análise da consolidação e do aperfeiçoamento do Estado protetor do ambiente na ordem jurídica brasileira, elucidando alguns princípios como exemplo ao mesmo tempo em que sustentáculo de tal sistema. O presente trabalho tem como objetivo investigar a principiologia ambiental na seara constitucional. Com tessitura bibliográfica foram utilizados os métodos lógico-dedutivo e dissertativo-argumentativo, a partir dos dados obtidos na formulação do texto. Diante deste arcabouço normativo, ainda é ressaltado a importância dos princípios constitucionais ambientais para compreender os fundamentos do Estado Democrático de Direito e, de outro modo, balizar todo e qualquer ato prejudicial que o ser humano possa fazer contra o ambiente.
\end{abstract}

Palavras-chave: Principiologia constitucional. Estado protetor. Salvaguarda. Direitos. Ato prejudicial.

\footnotetext{
* Doutor em Direito pela Universidade Federal de Pernambuco. Professor titular da Universidade do Estado do Rio Grande do Norte, e Professor Associado II da Universidade Federal do Rio Grande do Norte (UFRN). Coordenador Operacional do Doutorado Interinstitucional (DINTER) em Direito da Universidade do Estado do Rio Grande do Norte (UERN) em convênio com a Universidade Federal do Paraná (UFPR). E-mail: s.alexandre.prof@gmail.com
}

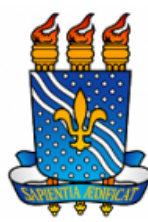

UNIVERSIDADE FEDERAL DA PARAÍBA

Programa de Pós-Graduação em Ciências Jurídicas

DOI: https://doi.org/10.22478/ufpb.1678-2593.2021v20n44.46055 


\title{
Direito Ambiental Constitucional: Uma Perspectiva Principiológica Normativista
}

\author{
Sérgio Braga Júnior
}

\section{INTRODUÇÃO}

A Constituição Federal de 1988, conhecida entre outros nomes por Constituição Ambiental, já que dedica um amplo capítulo a este direito difuso da $3^{\mathrm{a}}$ geração, regula a proteção da fauna e da flora, almejando que não sejam afetados por eventuais práticas cruéis provocadas pelo ser humano.

Ocorre que, para tratar de qualquer questão que envolva direitos fundamentais - construções normativas que visam contemplar o princípio da dignidade da pessoa humana - deve-se ter um olhar atento e ponderado, a fim de que não haja restrições ilegítimas ao indivíduo no exercício de tais direitos nem prejuízo à fauna e à flora, em se tratando de uma questão ambiental.

Não se torna possível delimitar o "meio ambiente" fora de uma visão de cunho antropocêntrico, pois sua proteção depende da atividade humana, nesse sentido, afirma a teoria do "antropoceno" que a era geológica mais recente é denominada antropoceno, a qual tem com principal caraterística as fortes intervenções antrópicas. Os sinais dessa intervenção(humana) estão em várias partes do mundo, na ocorrência de furacões e chuvas torrenciais, e no derretimento de gelo na Groenlândia, entre outros acontecimentos. A consequência disso seria o aumento da temperatura da terra nos próximos 100 anos entre $1^{\circ}, 5^{\circ}$ e $3^{\circ}$. Para evitar essas previsões, a sociedade precisaria tomar algumas providências, como adotar melhores práticas agrícolas, evitar o desmatamento e usar veículos menos poluentes. Nesse 
contexto, se verifica a interface com todos os integrantes da sociedade, implicando a modificação radical da relação dos seres humanos para com o meio ambiente, algo que não será alcançado somente com a obediência legislação atual ou qualquer outra que venha a ser criada.(SOCIEDADE BRASILEIRA PARA O PROGRESSO DA CIÊNCIA, 2010).

Nesse sentido, Bottini (2007, p. 32) leciona que, hodiernamente, os indivíduos estão diante da denominada sociedade de risco, resultado do desenvolvimento de um modelo econômico nascedouro da Revolução Industrial, que organizava a produção de bens através de um sistema de livre concorrência. Esse modelo econômico exige que os agentes de produção busquem inovação tecnológica para permitir a produção e distribuição em larga escala de insumos, sob pena de se tornarem obsolescentes ao não acompanhar os avanços tecnológicos. A produção artesanal foi transmutada na produção industrial, ao adicionar tecnologias inovadoras, a mesma acabou alcançando mais consumidores e reduzindo custos.

Em virtude da heterogeneidade dos direitos fundamentais, remanesceu ao Estado o dever de formular instrumentos destinados a garantir essas medidas de forma equitativa às partes envolvidas, a fim de se evitar a colisão desses direitos. Neste sentido, para que os conflitos de direitos fundamentais na seara ambiental sejam dirimidos de forma mais prudente, o Estado, desde 1988, adotou uma posição reguladora, visando a proteger aquele que mais se encontra em situação de vulnerabilidade nesses casos: o ambiente. Luta-se, nesses casos, não só por uma coexistência harmoniosa de direitos do ambiente e do ser humano, mas também por uma proteção e preservação do meio para as gerações futuras.

Conforme apontou Silva (2007), embora as ações normativas não consigam eliminar os conflitos causados pela inovação, tais ações desempenham um papel intermediário ao propor modelos de ajuste para regular os conflitos. Entre os princípios que norteiam as ações de gestão de riscos de indivíduos, organizações e países, o princípio da 
precaução adotado pela Conferência das Nações Unidas sobre Meio Ambiente e Desenvolvimento em 1992 e institucionalizado no ambiente jurídico ambiental permite a implementação do modelo de ajuste de conflitos socioambientais de nanotecnologia, pois geralmente ocorre, em qualquer nova tecnologia ou material sintético com potencial de aplicação comercial (MORAIS, 2016, p. 429).O princípio estabelece que:

Com o fim de proteger o meio ambiente, o princípio da precaução deverá ser amplamente observado pelos Estados, de acordo com suas capacidades. Quando houver ameaça de danos graves ou irreversíveis, a ausência de certeza científica absoluta não será utilizada como razão para o adiamento de medidas economicamente viáveis para prevenir a degradação ambiental. DECLARAÇÃO DO RIO DE JANEIRO SOBRE MEIO AMBIENTE E DESENVOLVIMENTO, 1992, princípio 15).

Bottini (2007, p.33) designa a fixação por um rápido desenvolvimento tecnológico implica no aumento de velocidade com que novas descobertas tecnológicas são feitas, as quais são, em sua maioria, decorrência do financiamento de pesquisas científicas destinadas a tais finalidades. Este fenômeno cria uma dinâmica peculiar, pois a intensidade do progresso da ciência não é acompanhada pela análise, por parte desta mesma ciência, dos efeitos decorrentes da utilização destas novas tecnologias. A criação de novas técnicas de produção não é seguida pelo desenvolvimento de instrumentos de avaliação e medição dos potenciais resultados de sua aplicação.

Descobriu-se, desse modo, que o desenvolvimento das atividades econômicas existentes não é plenamente compatível com o meio ambiente, o que tem criado um risco incalculável para o país. Como Ulrich Beck (1998, p. 23) apontou, isso ocorre porque as características dos riscos anteriores foram mais fáceis de medir ou prever.

Afinal, é sabido que os constantes avanços tecnológicos e sociais trouxeram e trazem cada vez mais diversos benefícios para a humanidade, ao tempo em que consumiram e consomem desenfreadamente os recursos naturais para tanto. É justamente nessa 
lógica e com a consciência de que os recursos ambientais são, em regra, finitos e limitados e a ambição e o progresso humano infinitos e ilimitados, que se entende necessário o papel do Estado na tutela dos direitos ambientais.

\section{A CONSOLIDAÇÃO E O APERFEIÇOAMENTO DO ESTADO PROTETOR AMBIENTAL}

Preliminarmente, já foi dada uma noção de que o ambiente e os seus recursos são frágeis e finitos diante do poder e da ganância do ser humano. Mas do que se trata, em linhas mais técnicas, esse meio ambiente ${ }^{1}$ que tanto precisa de proteção?

Uma das conceituações mais precisas é a do Conselho Nacional do Meio Ambiente, o CONAMA, em sua Resolução 306/2002 - semelhante à definição trazida pelo art. $3^{\circ}$ da Lei n ${ }^{0} .6 .938 / 81$ - que define o ambiente como o "conjunto de condições, leis, influências e interações de ordem física, química, biológica, social, cultural e urbanística, que permite, abriga e rege a vida em todas as suas formas". Assim, fica evidente que se trata de uma abordagem inter e transdisciplinar nesta perspectiva de definição.

Destarte, a interdisciplinaridade implica, então, em um procedimento de inter-relação de processos, conhecimentos e práticas que transborda e transcende o campo da pesquisa e do ensino no que se refere estritamente às disciplinas científicas e a suas possíveis articulações. Dessa maneira, o termo interdisciplinaridade vem sendo usado como sinônimo de interconexão e "colaboração" entre diversos campos do conhecimento e do saber dentro de projetos que envolvem tanto as diferentes disciplinas acadêmicas (LEFF, 2014, p. 3) como as

\footnotetext{
${ }^{1}$ A título informativo, sabe-se que a expressão "meio ambiente" (milieu ambiant) foi utilizada pela primeira vez pelo naturalista francês Geoffroy de Saint-Hilaire na obra Études progressivos d'um naturaliste, de 1835, tendo sido perfilhada por Auguste Comte em seu Curso de filosofia positiva. MILARÉ, Édis. Direito do Ambiente. 10. ed. rev., atual. e ampl. São Paulo: Editora Revistas dos Tribunais. 2015, p.168.
} 
práticas não científicas que permeiam as instituições e atores sociais diversos.

Segundo Leila da Costa Ferreira (2006), as discussões interdisciplinares são objeto de constante debate, mas ainda não há consenso. O que se pode dizer dessa polêmica é que, em linhas gerais, existem dois pontos de vista distintos: o primeiro ponto de vista aproxima o diálogo entre as disciplinas científicas, a fim de ampliar a interpretação dos objetos de conhecimento da disciplina, como as questões ambientais. A sociologia ambiental buscada interage teoricamente em determinadas áreas de convergência. A segunda visão da construção interdisciplinar se limita ao campo da pesquisa especial e se opõe à visão da assimilação gradual entre as disciplinas. Segundo Floriani (2004, p. 32), essa visão reconhece as peculiaridades da disciplina, mas se vale de uma colaboração deliberada de saberes disciplinares sobre um tema previamente definido.

Em termos doutrinários e assumindo uma perspectiva mais ampla de tal conceito, José Afonso da Silva (2003, p. 20) afirma que o meio ambiente seria a interação dos "conjuntos de elementos naturais, artificiais e culturais que propiciem o desenvolvimento equilibrado da vida em todas as suas formas".

Sobre o conceito jurídico do meio ambiente, o Superior Tribunal de Justiça ${ }^{2}$ firmou entendimento que:

\begin{abstract}
A legislação federal brasileira que trata da problemática da preservação do meio ambiente é expressa, clara e precisa quanto à relação de continência existente entre os conceitos de loteamento, paisagismo e estética urbana e o conceito de meio ambiente, sendo que este último abrange os primeiros.
\end{abstract}

Ante as conceituações expostas, é possível ter uma noção maior de porque o meio deve receber a especial tutela do Estado como ora recebe. É fato que, no decorrer do século $\mathrm{XX}$, as nefastas

2 STJ - REsp n. 876931/RJ, Data de Julgamento: 10/o8/2010, Relator: Ministro Mauro Campbell Marques. Disponível em: https://stj.jusbrasil.com.br/jurisprudencia/1681916o/recurso-especial-resp876931-rj-2006-0115752-8/inteiro-teor-16819161?ref=juris-tabs. Acesso em 30 mai. 2018. 
manifestações dos impactos ambientais, acumuladas de séculos anteriores, ocasionadas e intensificadas pela ação antrópica proporcionaram uma crescente tomada de consciência pela população mundial.

Não só o Estado brasileiro, mas de modo geral, notou-se uma maior atenção dos países mundo afora na tutela do meio ambiente, com a percepção de que seria necessária uma proteção jurídica capaz de promover o equilíbrio dos ecossistemas ou então a geração atual e as futuras estariam com a sobrevivência seriamente ameaçada.

Ademais, deve-se considerar o modelo do Estado Democrático de Direito e o caráter próprio de salvaguarda de direitos a ele inerente, o que teve o seu surgimento e o seu crescimento acentuado no contexto pós-guerra. Foi exatamente neste momento que os direitos ambientais começaram a ser inseridos nas constituições de muitos países.

Em nível global, foi notável a Conferência das Nações Unidas realizada em Estocolmo em 1972. Ela reconheceu o direito básico das pessoas de desfrutar de um ambiente adequado para viver uma vida digna. Nas palavras de José Afonso da Silva (2003, p. 69), a Declaração de Estocolmo abriu caminho para que as posteriores Constituições reconhecessem o meio ambiente ecologicamente equilibrado como um direito fundamental entre os direitos sociais.

A formulação do Estado Ambiental de Direito implica definir um Estado que, "além de ser um Estado de Direito, um Estado Democrático e um Estado Social, deve também modelar-se como Estado Ambiental" (CANOTILHO, 1995a, p. 22).

Sendo assim, um bem ambiental não pode ser classificado como um bem público, pelo contrário, deve ser considerado um bem de interesse público, cuja administração, uso e gestão devem ser compartilhados e unidos a toda a comunidade e inspirados na democracia ambiental. Desse modo, em um país ambientalmente democrático, os bens ambientais devem pertencer à comunidade, ao invés de integrarem o patrimônio disponível do Estado, para evitar o 
uso irracional e autoritário do patrimônio ambiental por parte dos poderes públicos e privados (LEITE, 2000, p. 21).

Os Direitos Humanos e o Direito Ambiental consistem em dois polos interligados que se somam à produção integral e material da dignidade da pessoa humana (PIOVESAN, 2016, p. 43). Realçando a cumplicidade dos dois nortes dessa reflexão, Trindade (1993) assegura que a pauta da agenda contemporânea dos direitos humanos está centrada na proteção ao meio ambiente e ao desenvolvimento humano, e no combate à pobreza endêmica, para além de outras questões preocupantes, como o crescente armamentismo.

Em sentido idêntico, como assinala Mello (2001), a proteção internacional do meio ambiente deve estar ligada aos direitos do homem. Daí a proteção internacional dos direitos humanos e o Direito Internacional do Meio Ambiente terem sido considerados, por Soares (2002), como os dois primeiros grandes temas de globalidade. Faz-se mister inserir a proteção ao meio ambiente na agenda dos direitos humanos, tomando por base uma compreensão holística e irrestrita desses direitos (PIOVESAN, 2016, p.44).

No Brasil, como já elucidado, a questão ambiental obteve maior destaque e aparato estatal a partir da Constituição de 1988. Nesse sentido, Milaré (2015, p. 169) assevera que, nas Constituições brasileiras anteriores à Ambiental, jamais foi retratado qualquer cuidado com a proteção do ambiente de forma específica e global. Nestas, nem mesmo uma vez foi empregada a expressão "meio ambiente", transmitindo a ideia de despreocupação, cosmovisão que era, até então, predominante, tendo em vista que a preocupação da comunidade internacional com o meio ambiente e a finitude de seus recursos remontam o final da década de 70 .

Assim, foi somente em 1988, com a Constituição Federal, segundo os arts 23 e 24, respectivamente, que se atribui aos entes federativos poderes administrativos de forma diferenciada, a competência administrativa para proteger o meio ambiente, o combate à poluição, a preservação da flora e fauna, bem como legislar, concorrentemente. 
Mas é certo que a proteção do meio e sua devida motivação estejam mais explícitas no caput 3 do art. 255, CF/88, o qual inicia o capítulo do meio ambiente na Lex Mater. Expõe o bem comum como causa, ao passo que decorre de um ambiente ecologicamente equilibrado. Assim, está claro que este bem de "uso comum do povo" gera a felicidade deste e proporciona a sadia qualidade de vida, embasando e reiterando a necessidade da proteção do Estado para o usufruto deste bem por toda a Nação.

Se analisarmos a própria definição de Direito Ambiental, que segundo Talden Farias (2010, p. 168), pode ser entendido como um ramo do direito que regula "a apropriação econômica dos bens ambientais, de forma que ela se faça levando em consideração a sustentabilidade dos recursos, o desenvolvimento econômico e social, bem como padrões adequados de saúde e renda”, pode-se perceber que a abrangência de campos e ciências que ela alcança é demasiadamente larga.

Faz-se necessário, desse modo, diálogo com outras ciências, como a Ecologia, a Biologia, a Geologia, a Geografia, entre outras, as quais se aproximam da complexidade do estudo científico do meio ambiente (PADILHA, 2010), que enquanto objeto de conhecimento humano, só pode ser alcançado em sua totalidade por meio do estudo interdisciplinar.

Nos dizeres de Milaré (2018, p. 171), a esse texto - secundado pelas Cartas estaduais e Leis Orgânicas municipais - somaram-se novos e copiosos diplomas oriundos de todos os níveis do Poder Público e da hierarquia normativa voltados à preocupação do já tão desfalcado patrimônio natural nacional. Como exemplo, há a Lei $\mathrm{n}^{\mathrm{o}}$ 8.746/93, que cria o Ministério do Meio Ambiente e a Lei no 9.795/99, referente à Política Nacional de Educação Ambiental.

\footnotetext{
3 Art. 225. Todos têm direito ao meio ambiente ecologicamente equilibrado, bem de uso comum do povo e essencial à sadia qualidade de vida, impondo-se ao Poder Público e à coletividade o dever de defendê-lo e preservá-lo para as presentes e futuras gerações.
} 
Salienta-se o papel da educação ambiental na sensibilização das pessoas, por meio de uma proposta reflexiva, com vistas à transformação de condutas e posturas, propiciando a correção de valores individuais e coletivos, algo crucial em uma realidade de degradação permanente do meio ambiente e de seus ecossistemas, como a contemporânea (JACOBI et al., 2009).

A principiologia, discricionariamente elegida, a seguir, retrata os ditames constitucionais ambientais que orientam o estudo e a prática da preservação de nossos recursos naturais, como os elencados no art.20 da CF/88.

\section{OS PRINCÍPIOS FUNDAMENTAIS EM MATÉRIA AMBIENTAL NA CONSTITUIÇÃO BRASILEIRA}

R. Dworkin (1977, p. 22) chama de princípio aquele standard que deve ser observado, não por ter em vista uma finalidade econômica, política, ou social, que se possa considerar favorável, mas porque seja uma exigência de justiça, ou equidade, ou alguma outra dimensão de moralidade. Em suma, o autor sustenta que os princípios são proposições que descrevem direitos; diretrizes (políticas) são proposições que descrevem objetivos. Por isso que, em geral, os argumentos de princípios se predispõem à defesa de direitos do indivíduo, enquanto argumentos políticos se propõem à defesa de interesses da coletividade (DWORKIN, 1977, p. 90).

O Direito Ambiental Constitucional é embasado por princípios e regras assentes na Carta Magna Brasileira. Os princípios ambientais são os pressupostos básicos de um sistema jurídico que guiam a interpretação e a aplicação das demais normas jurídicas, encontrando respaldo em declarações internacionais. Tal fator proporciona a crescente potencialidade de estes se tornarem normas costumeiras, quando não se transformarem em normas jurídicas oriundas de convenções. 
Um setor estratégico, é a gestão ambiental, dentro dessa nova política institucional, prevista na Lei $\mathrm{n}^{0}$. 6.938/81, que está guiada por princípios de descentralização e melhoria das camadas sociais.

De acordo com Cunha e Coelho (2008), desde meados da década de 1980, e mais propriamente, após a promulgação da Constituição Federal, o processo de formulação e implementação das políticas ambientais no país tem se tornado cada vez mais um produto da interação de ideias e valores. As estratégias de ação dos participantes situam-se em um campo marcado por conflitos, alianças e contradições, campos esses que surgem pelos múltiplos interesses relacionados nas questões de proteção ambiental (MELO, 2010).

O Direito é eminentemente ético ou, como ensina Jellinek (1943, p. 27), é o "minimum" ético, aquela porção da Ética que é indispensável à convivência social. Teoria esta contraposta, na atualidade, pela idealização dos círculos secantes entre a moral e o direito.

Nas palavras de Del Vecchio (1999, p. 336), "el Derecho constituye la Ética objetiva, y, en cambio, la Moral la Ética subjetiva". A Ética seria, portanto, a Moral do ponto de vista subjetivo (atitude em relação ao próprio sujeito - unilateral), ao passo que o Direito é a Moral sob o prisma objetivo (atitude em relação aos outros - bilateral).

De qualquer forma, a despeito da norma ética ambiental ser sempre lógica e cronologicamente anterior à norma jurídica, esta inequivocamente se situa no âmbito da normatividade ética/principiológica. A partir da Conferência ECO-92, realizada no Rio de Janeiro, ganhou especial destaque na mídia a importância da ecologia e da preservação do meio ambiente, assim como o reconhecimento das proporções da sua devastação pela ação humana.

De um modo geral, os princípios ambientais estão expressos na Constituição pelos diferentes graus de eficácia e obedecem a uma hierarquia no sistema, no qual nenhuma norma está autorizada a violar os princípios constitucionais, que guardam relação de subordinação entre si. Serão expostos alguns princípios entendidos 
como indispensáveis para que a temática deste artigo seja melhor sedimentada.

\subsection{Princípio do Desenvolvimento Sustentável}

A despeito de a Constituição de 1988 e de algumas leis infraconstitucionais - até mesmo anteriores a esta, como a Lei $\mathrm{n}^{\mathrm{o}}$ 4771/1965, caso em que está plenamente justificado, ante a ausência de um forte caráter normativo-protetor do ambiente - colocarem o homem como principal beneficiário, haverá casos em que para se conservar a vida humana o meio ambiente é imediatamente prioritário em termos de proteção. Desse modo, o homem pode usufruir e, ao mesmo tempo, interferir nos bens ambientais por meio do consumo, da poluição e da contemplação.

De acordo com a legislação brasileira, de acordo com o princípio do desenvolvimento sustentável (regionalização), o uso prioritário de bens ambientais deve respeitar a ordem de proximidade entre usuários e bens. Portanto, é necessário respeitar o uso de produtos por usuários que atendam a proximidade local, regional e nacional. Todavia, efetivamente, pouco se observa sobre o tema.

Isto posto, nota-se que o princípio do Desenvolvimento sustentável está capitulado no art. 170, IV, bem como no caput do art. 225, ambos da Constituição de 1988. Ainda, encontra previsão no princípio 03 - O direito ao desenvolvimento deve ser realizado de forma "a permitir que sejam atendidas equitativamente as necessidades de desenvolvimento e de meio ambiente das gerações presentes e futuras" - e princípio 04 - "Para alcançar o desenvolvimento sustentável, a proteção ambiental constituirá parte integrante do processo de desenvolvimento e não pode ser considerada isoladamente deste"-, ambos provenientes da Declaração do Rio4.

4 Repise-se que a Declaração do Rio de 1992 não tem a natureza jurídica de tratado internacional para o Brasil, sendo uma espécie de compromisso mundial ético, tal qual a Declaração da ONU de 1948. 
Já no âmbito doutrinário, está pacificado o termo "meio ambiente ecologicamente equilibrado", oriundo do art. 225 da Lex Mater. Entende-se, para isso, a harmonia entre meio ambiente natural, cultural, de trabalho e o homem, visto que a legislação ambiental e a Constituição Federal colocam o homem no topo das tutelas.

Para Frederico Amado (2014, p. 63), o desenvolvimento sustentável é aquele que atende às necessidades do presente sem comprometer a possibilidade de existência digna das gerações futuras. E Amado ainda complementa (2014, p. 61): Este princípio decorre de uma ponderação que deverá ser feita casuisticamente entre o direito fundamental ao desenvolvimento econômico e o direito à preservação ambiental, à luz do Princípio da Proporcionalidade. É a ponderação, já tratada na introdução destes escritos, tão necessária nos casos em que ocorre colisão de direitos fundamentais. Melhor nos explica J. Canotilho (1999, p. 1191):

\begin{abstract}
De um modo geral, considera-se existir uma colisão de direitos fundamentais quando o exercício de um direito fundamental por parte do seu titular colide com o exercício do direito fundamental por parte de outro titular. Aqui não estamos diante de um cruzamento ou acumulação de direitos (como na concorrência de direitos), mas perante um choque, um autêntico conflito de direitos (grifo nosso).
\end{abstract}

É necessário sopesar esses direitos conflitantes e proceder a análise madura e sóbria tanto quanto possível, pois é indubitável que a destruição ambiental prejudica a possibilidade do ser humano também existir com dignidade - não há como imaginar que o ser humano seja independente da natureza. O homem faz parte da natureza e depende dela, portanto, o equilíbrio é mútuo. Todavia para entender os princípios do desenvolvimento sustentável, é preciso compreender que equilíbrio ecológico não condiz com a absoluta imutabilidade das condições naturais, mas sim uma singela harmonia.

O Estatuto da Cidade, (Lei ${ }^{0}$ 10.257/2001), regulamentando a Política Urbana, presente nos arts. 182 e 183 da Constituição Federal, 
também prima pelo desenvolvimento sustentável, que é um dos alicerces do Direito Ambiental, sendo expresso no caput do art. 225 da $\mathrm{CF} / 88$, como direito fundamental do homem. Com relação à sustentabilidade, o Estatuto da Cidade faz referência expressa ao direito à moradia, saneamento, infraestrutura urbana, transporte, serviços públicos, trabalho e lazer e adoção de padrões de produção e consumo de bens e serviços e de expansão urbana compatíveis com esse conceito (CAPPELI, 2014).

Ainda no tocante às políticas públicas, um dos grandes avanços verificados se deu com a edição da lei n ${ }^{0} 6.938 / 81$, conhecida como Lei da Política Nacional do Meio Ambiente-PNMA. Edis Milaré (2009, p. 235) explica que as ações governamentais que tratavam do meio ambiente eram decididas muitas vezes de forma arbitrária, e geralmente seguiam as tendências do governo à época, sem ser realizado nenhum plano, programa e projetos devidamente articulados. Com a implementação da PNMA, diz Milaré (2009, p.236), as medidas ganharam estabilidade e o alcance de perspectivas de política a longo prazo. Em relação ao termo "como bem essencial à sadia qualidade de vida" percebe-se que ele está atrelado à ideia de meio ambiente ecologicamente equilibrado, fazendo que a conservação do meio ambiente ecologicamente equilibrado proporcione uma sadia qualidade de vida. Ainda analisando este princípio e o art. 225 da CF que o contempla, o Poder Público age como gestor do meio ambiente - traduzido pela expressão "bem de uso comum do povo"-, e não, equivocadamente, "proprietário de bens ambientais".

Em contrapartida ao que foi apontado, é mister destacar a crítica feita pela Escola da "Justiça Ambiental" ao conceito de Desenvolvimento Sustentável, sendo que, conforme Acselrad (2002), um dos principais autores que decompôs essa noção no Brasil, o referido conceito foi a maneira encontrada para reagir perante os impactos negativos do progresso industrial, o que culminou na incorporação do capital ambiental e no abandono em relação a visão 
de que a natureza é um bem livre, haja vista que a ela lhe é atribuída um "preço justo".

\subsection{Princípio da Precaução}

O princípio em tela, previsto de modo implícito na Constituição de 1988, traz à baila a inversão do ônus da prova, tão cara em matéria de direito ambiental, haja vista o caráter de necessária proteção ao meio. Nesta situação, não cabe ao acusador o ônus de provar a imputação, mas sim quem praticou o ato está incumbido de provar que não o fez.

Dessa forma, o princípio da Precaução está previsto no Princípio 15 da Declaração do Rio de Janeiro de 1992, in lliteris:

Com o fim de proteger o meio ambiente, o princípio da precaução deverá ser amplamente observado pelos Estados, de acordo com suas capacidades. Quando houver ameaça de danos graves ou irreversíveis, a ausência de certeza científica absoluta não será utilizada como razão para o adiamento de medidas economicamente viáveis para prevenir a degradação ambiental.

Melhor aduzindo, estão as lições de Frederico Amado (2014, p.57):

[...] se determinado empreendimento puder causar danos ambientais sérios ou irreversíveis, contudo inexiste certeza científica quanto aos efetivos danos e a sua extensão, mas há base científica razoável fundada em juízo de possibilidade não remoto da sua potencial ocorrência, o empreendedor deverá ser compelido a adotar medidas de precaução para elidir ou reduzir os riscos ambientais para a população.

Em um estudo comparado, no entendimento de Édis Milaré (2015, p.264 e 265), nota-se que:

A inovação do principio da precaução é uma decisão a ser tomada quando a informação científica é insuficiente, inconclusiva ou incerta e haja indicações de que possíveis efeitos sobre o ambiente, a saúde das pessoas ou dos animais ou a proteção vegetal possam ser potencialmente perigosos e incompatíveis com o nível de proteção escolhido. 
Resta claro que o princípio da precaução controla e embasa a vedação de intervenções no meio ambiente, salvo nos casos em que haja a percepção exata de que essas mudanças não irão causar reações adversas, pois a ciência nem sempre pode fornecer à sociedade evidências comprováveis sobre a segurança de determinados procedimentos.

Importante frisar que Paulo de Bessa Antunes (2004, p. 41) acredita que obstáculos a uma atividade baseada no princípio da precaução só podem ocorrer quando existem razões legítimas baseadas em padrões científicos validados pela comunidade internacional, pois, não raro, são presenciadas opiniões isoladas utilizadas como "pretexto" para a interrupção de experiências e projetos que, muitas vezes, são socialmente relevantes. Por fim, mister citar a EPIA e o RIMA, como exercício do poder da precaução, com as respectivas resoluções do CONAMA 237 e 001 de 1986.

O Tribunal Regional Federal -TRF da $1^{\mathrm{a}}$ região5 estabelece magistralmente a diferença entre o princípio da precaução com o da prevenção:

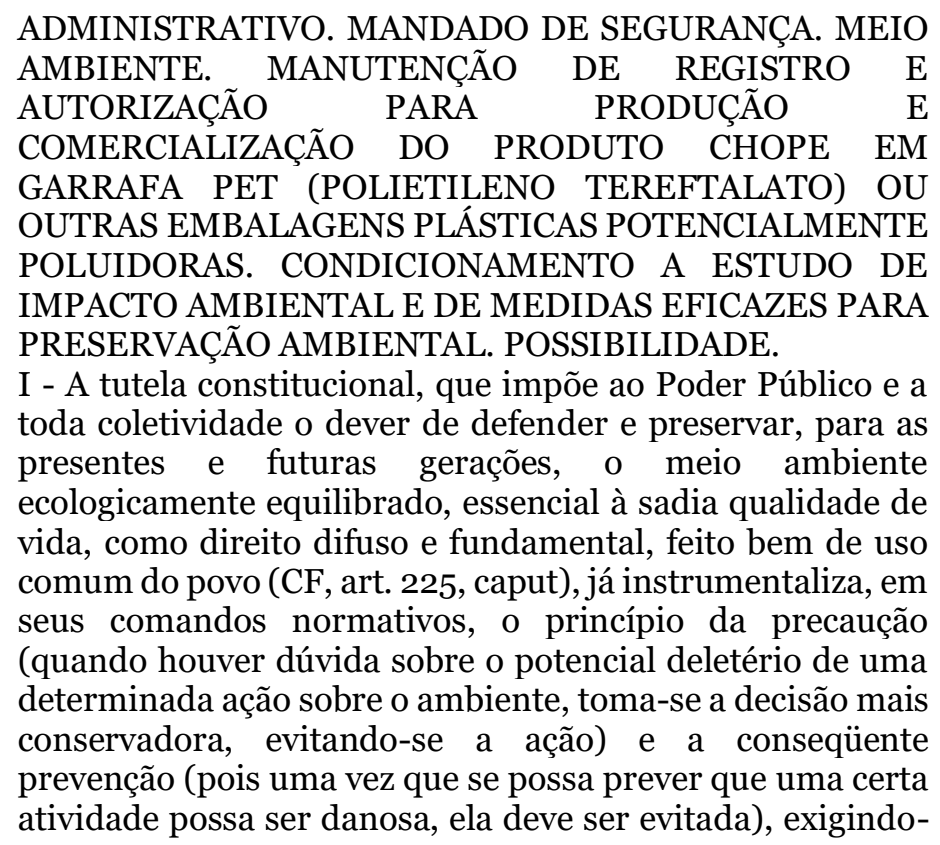

5 Tribunal Regional Federal -TRF da ${ }^{\text {a }}$ região -Processo: 200634000095127 UF: DF Órgão Julgador: SEXTA TURMA-Data da decisão: 11/06/2007 Documento: TRF10254643 TRF 1 a região 
se, assim, na forma da lei, para instalação de obra ou atividade potencialmente causadora de significativa degradação do meio ambiente, estudo prévio de impacto ambiental, a que se dará publicidade (CF, art. 225, § $1^{\circ}$, IV).

\subsection{Princípio do Poluidor-Pagador}

Por outro lado, o princípio do poluidor-pagador estipula que quem utiliza os recursos ambientais deve arcar com os custos, e a taxa não acarretará na cobrança de abusos, ou de imposições abusivas, de forma que autoridades públicas e terceiros não serão afetados por tais custos. Em outras palavras, ao causar degradação ambiental, os poluidores violam a propriedade de todas as pessoas que respeitam o meio ambiente e também os direitos coletivos e difusos.

A Declaração do Rio de Janeiro sobre Meio Ambiente e Desenvolvimento de 1992, também dispôs sobre o princípio do poluidor-pagador ao estabelecer no Princípio 16, in verbis:

Tendo em vista que o poluidor deve, em princípio, arcar com o custo decorrente da poluição, as autoridades nacionais devem procurar promover a internacionalização dos custos ambientais e o uso de instrumentos econômicos, levando na devida conta o interesse público, sem distorcer o comércio e os investimentos internacionais.

Ao se analisar o art. $4^{\circ}$ da Lei $\mathrm{n}^{\mathrm{o}} 6.938 / 81$, na segunda parte do inciso VII, prevê-se o princípio do poluidor-pagador ao determinar que a Política Nacional do Meio Ambiente-PNMA visará à imposição ao usuário de contribuição, haja vista os fins econômicos da utilização de recursos ambientais nesse desiderato.

Frise-se, ademais, que tal princípio inspirou o $\S 1^{\circ}$ do art. 14 da Lei $n^{0} 6.938 / 1981$, ao prevê que o poluidor é obrigado, independente da existência de culpa a indenizar ou reparar os danos causados ao meio ambiente e a terceiros que sejam afetados por atividades 
praticadas por ele. Quanto a esta temática, o Superior Tribunal de Justiça ${ }^{6}$ possui entendimento firmado, in verbis:

Pacífica a jurisprudência do STJ de que, nos termos do art. 14, $\S 1^{\circ}$, da Lei 6.938/1981, o degradador, em decorrência do princípio do poluidor-pagador, previsto no art. $4^{\mathrm{o}}$, VIII (primeira parte), do mesmo estatuto, é obrigado, independentemente da existência de culpa, a reparar - por óbvio que às suas expensas - todos os danos que cause ao meio ambiente e a terceiros afetados por sua atividade, sendo prescindível perquirir acerca do elemento subjetivo, o que, consequentemente, torna irrelevante eventual boa ou má-fé para fins de acertamento da natureza, conteúdo e extensão dos deveres de restauração do status quo ante ecológico e de indenização.

Por fim, Frederico Amado (2014, p. 67), em sua obra, faz uma ressalva importante quanto a este princípio. Senão, veja-se:

Ressalte-se que este Princípio não deve ser interpretado de forma que haja abertura incondicional à poluição, desde que se pague (não é pagador-poluidor) só podendo o poluidor degradar o meio ambiente dentro dos limites de tolerância previstos na legislação ambiental, após licenciado.

\section{A BALIZA EXERCIDA PELOS PRINCÍPIOS AMBIENTAIS AOS ATOS PREJUDICIAIS DO HOMEM AO MEIO}

Ressalta-se, através de Lenio Luiz Streck (2014. p. 43), que embora o direito seja considerado um mecanismo de transformação social, ele é disfuncional, consubstanciado no dogma jurídico do modelo do individualismo liberal, não podendo atender às necessidades de uma sociedade transmoderna, densa em conflitos interpessoais.

Para melhor compreender como se dá o sistema de "criação" de balizas aos atos nocivos do homem em relação ao ambiente, se é que assim pode ser chamado, é necessário que se valha de uma comparação. José Afonso da Silva pontua (2003, p. 69) que os direitos

${ }^{6}$ STJ - trecho extraído do REsp no ${ }^{0}$ 769.753, de 08.09.2009. 
ambientais devem ser realizados e não perturbados. Neste ponto, é interessante traçar um paralelo entre o entendimento de José Afonso da Silva e o de Robert Alexy.

Robert Alexy (2014, p. 71) defende arduamente a natureza dualista do direito é o fundamento mais essencial do não positivismo. Esta tese pressupõe que existem certas propriedades necessárias do direito que pertencem à sua dimensão fática ou real - a exemplo da coerção -, assim como outras propriedades que fazem parte da dimensão ideal ou crítica, que seria o caso da pretensão de correção.

$\mathrm{E}$ aqui podem ser observadas duas vertentes do direito ambiental: ao tempo em que exerce a coerção para que os direitos ambientais sejam realizados, atua com uma pretensão de correção, a fim de evitar que as garantias do meio e dos que nele habitam não sejam perturbadas. É neste sentido que se percebe a harmonia das teses elencadas pelos renomados juristas, servindo como premissa básica para a compreensão do caráter balizador dos princípios ambientais aos atos nefastos do homem.

O dever de "respeito integral”, nos escólios de Julio Marcelo Prieto Méndez (2013, p. 16), estudando as lições de Benavides Ordoñez, aduz três tipologias de obrigações, para os sujeitos passivos: 1) Evitar a obrigação de impedir o gozo natural, pela própria natureza, de tais direitos; 2) Todos, não apenas o Estado, têm a obrigação de cumprir esses direitos; e 3) Se seus direitos forem violados, eles têm a obrigação de proteger a natureza.

Afinal, observa-se que, no ordenamento jurídico nacional, as partes mais vulneráveis recebem especial proteção do aparato estatal, na defesa de algumas minorias - os consumidores, por exemplo, contam com o Código de Defesa do Consumidor (CDC), Lei $\mathrm{n}^{0}$ 8.078/1990; as crianças e os adolescentes são tutelados pelo Estatuto da Criança e do Adolescente (ECA), Lei no 8069/1990; os idosos se valem do Estatuto do Idoso, dentre outros exemplos. Diferentemente, portanto, não poderia ocorrer com o ambiente, já tão devastado frente à ilimitada ambição humana. 
É possível falar em dano ambiental quando se está diante de agressão contra o meio, causada por atividade econômica potencialmente poluidora ou por ato comissivo ou omissivo praticado por qualquer pessoa. No dano ambiental, o ideal é a recuperação do ambiente danificado, a fim de que a coletividade possa gozar do direito a um meio ambiente ecologicamente equilibrado. Ademais, o STJ hoje pacificou o entendimento acerca da admissibilidade do dano moral coletivo decorrente do dano ambiental.

Os princípios ambientais, neste aspecto, merecem atenção especial quando funcionam como balizas, para diminuir ou mesmo impedir a degradação ocasionada por atos lesivos de alguns seres humanos. Considerado o ambiente como um dos princípios da ordem econômica pátria, consoante o art. $170 \mathrm{da} \mathrm{CF} / 88$, todas as atividades econômicas no País devem ser realizadas em observância e plena concordância com as diretrizes ambientais.

Não raro, nota-se que o Poder Judiciário tem deixado de proteger efetivamente o meio ambiente por causa do atrelamento excessivo ao positivismo jurídico e da falta de consideração aos princípios jurídicos. Importante, neste sentido, mencionar a Lei $\mathrm{n}^{\mathrm{o}}$ 9.605/1998, a qual dispõe sobre sanções penais e administrativas derivadas de condutas e de atividades lesivas ao meio ambiente.

O Art. 70 do diploma legal supramencionado define a infração administrativa ambiental como "toda ação ou omissão que viole as regras jurídicas de uso, gozo, promoção, proteção e recuperação do meio ambiente". É norma em branco que será regulamentada via ato administrativo normativo federal, estadual e municipal.

Todavia, comparados com outras fontes de direito, os princípios desempenham um papel particularmente importante, pois além de servirem de regras em casos reais, eles também influenciam a geração de outras fontes de direito. As leis, precedentes jurisprudenciais, doutrinas e tratados e convenções internacionais são todos baseados neles, porque refletem o valor mais essencial da Ciência Jurídica. 
Esses princípios, por sua vez, têm valor normativo, não apenas valor de avaliação, interpretação ou argumentação, portanto, teleologicamente, são superiores a qualquer outra regra. É necessário somente ponderar a aplicação dos princípios ambientais com os demais direitos fundamentais constitucionalmente assegurados e não deixar a aplicação daqueles "de lado".

Ainda nos valendo do pensamento de Alexy (2014, p. 61), a” vida cotidiana do direito é cheia de casos difíceis que não podem ser decididos simplesmente com base no que foi autoritariamente expedido”. E o teórico não poderia ser mais prudente em sua colocação. Quer-se dizer que, a despeito de toda a salvaguarda de direitos ambientais pelo Estado protetor, deve-se analisar cada caso concreto, para que se vislumbre a solução mais adequada em cada caso e que se evite conflito de direitos fundamentais.

Para isso, a Constituição Federal de 1988, no art.174, na Ordem Econômica, elucida o papel do Estado: Art. 174. Como agente normativo e regulador da atividade econômica, o Estado exercerá, na forma da lei, as funções de fiscalização, incentivo e planejamento, sendo este determinante para o setor público e indicativo para o setor privado. Ressalta-se seu papel de fiscalização nas atividades econômicas. Segundo Manoel Gonçalves Ferreira Filho (1990, p. 436) a saúde do livre mercado depende, justamente, de ação estatal.

Aliás, é o art. 174 da Constituição Federal que fundamenta a possibilidade legal da existência de agências ${ }^{7}$ reguladoras, a criarem normas jurídicas. Evidentemente, a atuação das agências não é feita contra o livre mercado; muito ao revés, as agências desempenham papel fundamental para a saúde do mercado, ao prescrever regras de conduta (regulação), ao fiscalizar e punir (direito administrativo sancionador) os componentes do mercado que agirem de forma indevida, nociva ao mercado (MATOS E SILVA, 2010).

7 Como é de sabença geral, o vocábulo agência tem origem na palavra agency, que consiste, de acordo com o direito norte-americano, em uma autarquia com poder de regulação em campos específicos da economia. 
No exercício de poder de polícia o art.78 do Código Tributário Nacional designa seu papel de fiscalização:

\begin{abstract}
Art. 78. Considera-se poder de polícia atividade da administração pública que, limitando ou disciplinando direito, interêsse ou liberdade, regula a prática de ato ou abstenção de fato, em razão de intêresse público concernente à segurança, à higiene, à ordem, aos costumes, à disciplina da produção e do mercado, ao exercício de atividades econômicas dependentes de concessão ou autorização do Poder Público, à tranqüilidade pública ou ao respeito à propriedade e aos direitos individuais ou coletivos. (Redação dada pelo Ato Complementar $\mathrm{n}^{0} 31$, de 28.12.1966)

Parágrafo único. Considera-se regular o exercício do poder de polícia quando desempenhado pelo órgão competente nos limites da lei aplicável, com observância do processo legal e, tratando-se de atividade que a lei tenha como discricionária, sem abuso ou desvio de poder.
\end{abstract}

No que tange aos atributos relativos ao poder de polícia, temse principalmente três, os quais são comuns à boa parte dos atos administrativos no geral: discricionariedade, autoexecutoriedade e coercibilidade.

Para que a salvaguarda do Poder de Polícia Ambiental, segundo Rebbelo Filho (1999, p. 68) seja realizada, ela é como as atividades dos serviços públicos que limitam, regulam ou restringem direitos, liberdades ou interesses, suas atividades estão relacionadas à saúde da população, à proteção do ecossistema, à disciplina de produção e mercados, atividades econômicas ou outras atividades que dependem de concessões governamentais, autorizações / permissões, ou licenças que podem vir a causar poluição ou violação da natureza.

Todos os instrumentos previstos na Lei $n^{0}$. 6.938/81, que coordenam a Política Nacional do Meio Ambiente-PNMA, se coadunam com o exercício de poder de polícia ambiental, como previsto nos dez dispositivos do art. $9^{\circ}$, tais como: I - o estabelecimento de padrões de qualidade ambiental; II - o zoneamento ambiental; III - a avaliação de impactos ambientais; ou IV - o licenciamento e a revisão de atividades efetiva ou potencialmente 
poluidoras. Além de outras normativas ambientais coercitivas como a Lei de Crimes Ambientais, Lei no.9.605 de 1998, que busca coibir práticas deletérias ambientais. Isso sem contar com as competências e prerrogativas dos órgãos que compõem o SISNAMA-Sistema Nacional do Meio Ambiente, que também utilizam o poder de polícia ambiental.

Já que o meio ambiente ecologicamente equilibrado se trata de um bem de interesse de toda a coletividade, isto é, de um direito difuso, vez que afeta a todos os seres humanos indiscriminadamente, e não só individualmente, o inciso LXXIII do art. $5^{\circ}$ da CF/88 trouxe, em sua redação, uma regra de garantia, de modo que qualquer cidadão possui legitimidade para propor ação popular cujo objetivo seja anular um ato lesivo ao meio ambiente.

Nesta senda, o Supremo Tribunal Federal ${ }^{8}$ decidiu que, in verbis:

\begin{abstract}
A incolumidade do meio ambiente não pode ser comprometida por interesses empresariais nem ficar dependente de motivações de índole meramente econômica, ainda mais se se tiver presente que a atividade econômica, considerada a disciplina constitucional que a rege, está subordina, dentre outros princípios gerais, àquele que privilegia a "defesa do meio ambiente" (CF, art. 170, VI) que traduz conceito amplo e abrangente das noções de meio ambiente natural, de meio ambiente cultural, de meio ambiente artificial (espaço urbano) e de meio ambiente laboral.
\end{abstract}

Milaré ainda faz uma ressalva interessante no que se refere à tomada de consciência e à mudança de comportamentos pelo próprio homem ante ao sistema protetor em voga. Não basta só legislar; é preciso que as leis e os princípios sejam retirados dos papéis e cumpridos de fato. O brasileiro, modus in rebus, possui um "desrespeito generalizado, impunido ou impunível, à legislação vigente" (2015, p. 172). Se as determinações ambientais não forem cumpridas, o meio não só continuará sendo cada dia mais devastado, como sofrerá de um novo tipo de poluição, a "poluição regulamentar".

${ }^{8}$ STF - ADI-MC 3540, DJe 02.03.2006, Relator: Ministro José Celso de Mello Filho. Disponível em: http://redir.stf.jus.br/paginadorpub/paginador.jsp?docTP=AC\&docID=387260 $>$. Acesso em 30 mai. 2018. 
Partindo do conceito de educação ambiental baseado na conexão interdisciplinar das ciências naturais e das ciências sociais, passou-se para a visão da complexidade ambiental, que está aberta a diferentes compreensões do meio ambiente e a uma interrelação de conhecimentos. Com esta perspectiva, a base epistemológica e a abordagem hermenêutica convergem na construção da racionalidade ambiental, que é mobilizada pelo conhecimento ambiental, e o mesmo está gravado na relação de poder por meio da apropriação social da natureza e da cultura. (LEFF, 1986, 1994b, 2000).

\section{CONSIDERAÇÕES FINAIS}

Há uma indissociabilidade entre os aspectos sociais e ambientais, observados por meio aos constantes avanços tecnológicos e sociais que proporcionam cada vez mais diversos benefícios para a humanidade. Nesse contexto, o Estado, sobretudo por meio da Constituição de 1988, não poderia ficar inerte, deixando o ambiente sem qualquer proteção mais robusta ante ao mero desejo do mercado, os modelos econômicos e instituições políticas acabam por incentivar a desproteção referida.

Nesta esfera, a aplicação dos princípios se torna ainda mais importante por conta da enorme profusão legislativa na área, já que os entes federativos - União, Estados, Distrito Federal e Municípios legislam a respeito com bastante intensidade. Os princípios ambientais - a exemplo dos que foram citados no presente artigo atuam como balizas, ao passo que suscitam a mudança de comportamentos e a tomada de atitudes pelos indivíduos.

O Estado Democrático de Direito possui em seus fundamentos a defesa da seara ambiental, tanto na Ordem Econômica(Art.170 da $\mathrm{CF} / 88$ ), quanto no Cap.VI da Ordem Social(art.225 da $\mathrm{CF} / 88$ ), justamente por ser através de sua principiologia normativa, de iniciativa preventiva, objetivando não desnaturar nosso patrimônio ambiental. 
O Estado dirigente nacional fez uso dos instrumentos principiológicos para asseverar a sua missão preservacionista. Estes sempre serviram como diretrizes de políticas públicas nacionais, interativas ou não, para representar deontologicamente a identidade ambiental brasileira.

Por isso mesmo, tais princípios atestam certa independência de um ramo da Ciência Jurídica, de certa forma, recente e que, até pouco tempo, ainda era contestado: o Direito Ambiental Constitucional. E mais que isso! O ambiente frágil merece que essa tutela seja reconhecida e amplamente exercida, visto que os seus recursos são esgotáveis e limitados, por isso, precisam receber a devida proteção contra os atos prejudiciais da ganância humana diariamente. Além disso, sua apropriação privada, monopolista e irracional agrava e acelera tal escassez, como prenunciado pelo Clube de Roma.

Portanto, é preciso que o Poder Judiciário recorra efetivamente aos princípios jurídicos - e em especial aos princípios do Direito Ambiental-, com o objetivo de harmonizar a legislação ambiental e de garantir o direito humano fundamental ao meio ambiente ecologicamente equilibrado

Faz se necessário que o Poder Judiciário busque socorrer-se dos princípios jurídicos - fundamentalmente os do direito ambiental para harmonizar a legislação ambiental e garantir um dos direitos humanos básicos, para desfrutar de um meio ambiente ecologicamente equilibrado para a presente e para as futuras gerações, tal como está posto na Constituição de 1988 - não por acaso chamada de "Ambientalista”. Mas não basta só legislar; é preciso que as leis e os princípios sejam retirados dos papéis e cumpridos de fato.

Data de Submissão: 23/05/2019

Data de Aprovação: 28/01/2020

Processo de Avaliação: double blind peer review

Editor Geral: Jailton Macena de Araújo 
Editor de Área: Jailton Macena de Araújo

Assistente Editorial: Bruna Agra de Medeiros

\section{REFERÊNCIAS}

ACSELRAD, Henri. Desenvolvimento Sustentável: A Luta por um Conceito. Proposta: Experiências em Educação Popular.

Desenvolvimento e Meio Ambiente, Rio de Janeiro, v. 17, n. 56, p. 5-8, mar. 1993 .

ALEXY, Robert. O conceito e a natureza do direito. Tradução: Thomas da Rosa de Bustamante; 3. ed. São Paulo: Marcial Pons, 2016.

AMADO, Frederico Augusto Di Trindade. Direito Ambiental Esquematizado. 7. ed. São Paulo: Método. 2016.

ANTUNES, Paulo de Bessa. Direito Ambiental. $19^{\mathrm{a}}$ ed. São Paulo: Atlas, 2017. BECK, Ulrich. La sociedad del riego - hacia una nueva modernidad. Tradución de Jorge Navarro, Daniel Jiménez y Maria Rosa Borras. Barcelona: Paidós, 1998.

BOTTINI, Pierpaolo Cruz. Crimes de perigo abstrato e princípio da precaução na sociedade de risco. São Paulo: Editora Revista dos Tribunais, 2007.

BRASIL. Constituição da República Federativa do Brasil, de o5 de outubro de 1988. Disponível em:

http://www.planalto.gov.br/ccivil_03/constituicao/constitui\%C3\%A 7ao.htm. Acesso em: 17 maio 2018.

BRASIL. Lei $\mathrm{n}^{\mathbf{0}} 6.938$, de 31 de agosto de 1981. Dispõe sobre a Política Nacional do Meio Ambiente, seus fins e mecanismos de formulação e aplicação, e dá outras providências. Disponível em: http://www.planalto.gov.br/ccivil_03/Leis/L6938.htm. Acesso em 21 maio 2018.

BRASIL. Lei $\mathrm{n}^{0}$ 9.605, de 12 de fevereiro de 1998. Dispõe sobre as sanções penais e administrativas derivadas de condutas e atividades lesivas ao meio ambiente, e dá outras providências. Disponível em: http://www.planalto.gov.br/ccivil_03/Leis/L9605.htm. Acesso em 30 maio 2018. 
Direito Ambiental Constitucional: Uma Perspectiva Principiológica Normativista

teoria da Constituição. 3. ed. Coimbra: Almedina, 1999.

CANOTILHO, José Joaquim Gomes. Direito público do

ambiente. Coimbra: Faculdade de Direito de Coimbra, 1995.

CAPPELI, Sílvia. Breves Comentários aos Aspectos

Ambientais do Estatuto da Cidade. Disponível em:

http://www.mprs.mp.br/urbanistico/doutrina/id35.htm. Acesso em: 10 nov. 2018.

CAVALCANTI, Clóvis. Meio ambiente, desenvolvimento sustentável e políticas públicas. São Paulo: Cortez, 2002.

COIMBRA, José de Ávila. Considerações sobre a

Interdisciplinaridade. Disponível em:

http://www.ft.unicamp.br/vitor/processo-seletivo-2014/textoavila.pdf. Acesso em: 10 nov. 2019.

COMTE, Auguste. Curso de filosofia positiva.Madrid: Andrômeda, 1830 .

CUNHA, L. H.; COELHO, M. C. Política e gestão ambiental. In: CUNHA, S.; GUERRA, A. J. A questão ambiental: diferentes abordagens. Rio de Janeiro: Bertrand Brasil, 2008.

DEL VECCHIO, Giorgio. Filosofía Del Derecho. 9. ed. Barcelona: Bosch, 1983

DWORKIN, R. Taking Rights Seriously . [S.l.]: Bloomsbury, 1977

FARIAS, Talden. Direito Ambiental: o meio ambiente e os desafios da contemporaneidade. Belo Horizonte: Fórum, 2010.

FERREIRA FILHO, Manoel Gonçalves. Curso de direito constitucional, de acordo com a Constituição de 1988. 42. ed. São Paulo: Saraiva, 2016.

FERREIRA, Leila da Costa. Ambiente e sociedade na teoria social: construindo a interdisciplinaridade. Revista Teoria e Pesquisa, jan/jun de 2006. Disponível em:http://www.teoriaepesquisa.ufscar.br/index.php/tp/article/view File/15/6. Acesso em 14 de ago. 2019.

FLORIANI, D. Conhecimento, Meio Ambiente \& Globalização. Curitiba: Juruá, 2004.

FONSECA, Igor Ferraz e BURSZTYN, Marcel. A banalização da sustentabilidade. Entre o ecologicamente correto e a governança ambiental fortalecida. Brasília: IV Encontro Nacional da Associação Nacional de Cursos de Pós Graduação em Ciências Ambientais, 2008. Anais do anais. Disponível em: 
http://www.scielo.br/pdf/se/v24n1/a03v24n1.pdf. Acesso em: 15 ago. 2019.

GOMES, Valdir. Administração, meio ambiente e a qualidade de Vida: as redes urbanas e a governança pública. Cadernos de Administração, São Paulo, 2018.

GORCZEVSKI, Clóvis. Meio ambiente, Constituição e Políticas Públicas. Curitiba: Multideia, 2011.

IHU. Transdisciplinaridade: uma outra forma de pensar o mundo. Revista Humanitas Unisinos, Ano V, $\mathrm{n}^{0} 153$, 2005. Disponível em:

http://www.ihuonline.unisinos.br/media/pdf/IHUOnlineEdicao153. pdf. Acesso em 14 de agosto de 2014.

JACOBI, P. R. TRISTÃO, M.;FRANCO, M. I. G.. A função social da educação ambiental nas práticas colaborativas, participação e engajamento. Caderno CEDES, v. 29, n. 77, p. 63-79, jan/abr.2009.

JELLINEK, Georg. Teoría General del Estado.Tradução: Fernando Urruti. Buenos Aires: Albatros, 1943.

LEFF, Enrique. Complexidade, Interdisciplinaridade e Saber Ambiental.

file://C:/Users/alexandre/Documents/Interdisciplinariedade\%20\% 20e\%20saber\%20ambiental\%20-ENRIQUE\%2olEFF.pdf. Disponível em $10 / 11 / 19$

LEFF, E. Sobre la articulación de las ciencias en la relación naturaleza sociedad. In: LEFF, Enrique. (Ed.). Biosociología y articulación de las ciencias. México: UNAM, 1981.

LEFF, Enrique. Ambiente y articulación de ciencias. In: LEFF, E. (Coord.). Los problemas del conocimiento y la perspectiva ambiental del desarrollo. México: Siglo XXI, 1986.

LEFF, Enrique. Sociología y ambiente. In: LEFF, E. (Coord.). Ciencias sociales y formación ambiental. Barcelona: GEDISA/UNAM/PNUMA, 1994.

LEFF, Enrique. Saber ambiental: sustentabilidade racionalidad, complejidad, poder. México:

Siglo XXI/UNAM/PNUMA, 1998.

LEFF, Enrique. La racionalidad ambiental y el fi $\boldsymbol{n}$ del naturalismo dialéctico. Persona 2000 Sociedad, (n. esp.), marzo, 1999. 
Direito Ambiental Constitucional: Uma Perspectiva Principiológica Normativista

LEITE, José Rubens Morato. Estado de direito do ambiente: uma difícil tarefa. In: LEITE, José Rubens Morato (Org.). Inovações em direito ambiental. Florianópolis: Fundação José Arthur Boiteux, 2010.

MELLO, C. D. DE A. Curso de Direito internacional Público. 13. ed. Rio de Janeiro: Renovar, 2001.

MELO, Josandra. Ordenamento territorial e sustentabilidade: um diálogo possível?. Caminhos de geografia - revista on line, 2010. Disponível em: http://www.seer.ufu.br/index.php/caminhosdegeografia/article/vie w/15930. Acesso em: 10 nov. 2019.

MENDEZ, Júlio Marcelo Prieto. Derechos de la naturaleza: fundamento, contenido y exigibilidad jurisdiccional: nuevo Derecho Ecuatoriano. Quito: Centro de Estudios y Difusión del Derecho Constitucional, 2013.

MILARÉ, Édis. Direito do Ambiente. São Paulo: Editora Revistas dos Tribunais, 2018.

MILARÉ, Edis. Direito do Ambiente: A gestão ambiental em foco. São Paulo: Revista dos Tribunais, 2009.

MORAES, Antônio Carlos Robert. Meio ambiente e Ciências Humanas. São Paulo: Hucitec, 1997. pp. 29-35. Disponível em: http://www.kilibro.com/en/book/preview/105397/meio-ambientee-ciencias-humanas. Acesso em: 10 nov. 2019.

MORAIS, J. P. (ET ALL). DIREITO AMBIENTAL APLICADO À NANOTECNOLOGIA, IN: ROSSI, A. et all.(ORGS).Direito Ambiental: Direitos Fundamentais e o Direito Ambiental. Brasília: EMBRAPA, 2016.

ONU. Declaração do Rio sobre Meio Ambiente e Desenvolvimento de 1992. Disponível em: http://www.onu.org.br/rio20/img/2012/o1/riog2.pdf. Acesso em 20 mai. 2018.

PADILHA, Norma Sueli. O saber ambiental na sua interdisciplinaridade: contribuiçao para os desafios do direito ambiental. 2010. Disponível em: http://www.conpedi.org.br/manaus/arquivos/anais/fortaleza/4160. pdf. Acesso em: 10 nov. 2019.

PECCATIELlO, Ana Flávia Oliveira. Políticas públicas ambientais no Brasil: da administração dos recursos naturais à criação do Sistema Nacional de Unidades de Conservação. Disponível em: 
file://C:/Users/alexandre/Downloads/21542-92902-1-PB.pdf. Acesso em: 10 nov. 2019.

PHILLIPI, Arlindo. Interdisciplinaridade em ciências ambientais. Disponível em:

http://www.unievangelica.edu.br/files/images/Interdisciplinaridade \%20e\%20Ci\%C3\%AAncias\%20Ambientais\%20(3).pdf. Acesso em: 10 nov. 2019.

PIOVESAN, Flávia; FACHIN, Melina G. DIREITOS HUMANOS E PROTEÇÃO AO MEIO AMBIENTE, IN: ROSSI, A. et all.(ORGS).Direito Ambiental:Direitos Fundamentais e o Direito Ambiental. Brasília: EMBRAPA, 2016.

REBBElo FILHO, Wanderley. Guia Prático de Direito Penal Ambiental, Rio de Janeiro: Lumen Juris, 1999.

SANTOS, Milton. 1992: A redescoberta da natureza. São Paulo: Universidade de São Paulo, 1992. Aula inaugural da Faculdade de Filosofia, Letras e Ciências Humanas, 10-03-1992. Disponível em: http://www.scielo.br/scielo.php?script=sci_arttext\&pid=So10340141992000100007\&lng=es. Acesso em: 20 de agosto de 2019.

SILVA, Bruno Mattos. Limites constitucionais à ação estatal na economia. Disponível em: https://jus.com.br/artigos/14419/limitesconstitucionais-a-acao-estatal-na-economia/2. Publicado em 02/2010. Acesso em: 20 maio 2019.

SILVA, José Afonso da. Direito Ambiental Constitucional. São Paulo: Malheiros, 2019.

SILVA, S. T. Efetividade do direito ambiental diante das inovações tecnológicas do século XXI. Revista de Gestão Integrada em Saúde do Trabalho e Meio Ambiente, São Paulo, v. 1, n. 3, 2007

SOARES, G.F.S. Curso de Direito Internacional Público. São Paulo: Atlas, 2002.

SOCIEDADE BRASILEIRA PARA O PROGRESSO DA CIÊNCIA. Cientistas divergem sobre o papel do homem no aquecimento global. 2010. Disponível em: https://www.inovacaotecnologica.com.br/noticias/noticia.php?artig $\mathrm{o}=$ cientistas-visoes-opostas-papel-homem-aquecimentoglobal\&id=020175100729\#.XIaJzCJKjIU Acesso em 25 nov. 2019.

STREK, Lênio Luiz. Hermenêutica jurídica e(m) crise: uma exploração hermenêutica da construção do Direito. 11. ed. Porto Alegre: Livraria do Advogado, 2014. 
Direito Ambiental Constitucional: Uma Perspectiva Principiológica Normativista

SUPERIOR TRIBUNAL DE JUSTIÇA -STJ - REsp n. 876931/RJ, Data de Julgamento: 10/o8/2010, Relator: Ministro Mauro Campbell Marques. Disponível em:

https://stj.jusbrasil.com.br/jurisprudencia/1681916o/recursoespecial-resp-876931-rj-2006-0115752-8/inteiro-teor16819161? ref=juris-tabs. Acesso em: 30 mai. 2018.

SUPREMO TRIBUNAL FEDERAL -STF - ADI-MC 3540, DJe 02.03.2006, Relator: Ministro José Celso de Mello Filho. Disponível em:

http://redir.stf.jus.br/paginadorpub/paginador.jsp?docTP=AC\&docI $\mathrm{D}=387260$. Acesso em: 30 mai. 2018.

TRIBUNAL REGIONAL FEDERAL -TRF da $1^{\mathrm{a}}$ região -Processo: 200634000095127 UF: DF Órgão Julgador: SEXTA TURMA-Data da decisão: 11/06/2007 Documento: TRF10254643 TRF 1 a região.

TRINDADE, A. A. A. C. Direitos Humanos e meio ambiente.

Porto Alegre:Fabris, 1993. 


\title{
Constitutional Environmental Law: A Normativist Principiological Perspective
}

\author{
Sérgio Braga Júnior
}

\begin{abstract}
The scope of this article is primarily to address the safeguarding of rights brought about by the 1988 Constitution, relevant to the protection of natural and landscape heritage. We seek to promote an analysis of the consolidation and improvement of the protective state of the environment in the Brazilian legal order, elucidating some principles as an example while supporting this system. This paper aims to investigate the environmental principles in the constitutional area. With bibliographic texture the logical-deductive and dissertative-argumentative methods were used, based on the data obtained in the formulation of the text. Given this normative framework, the importance of environmental constitutional principles to understand the foundations of the Democratic Rule of Law and, in other way, to mark any harmful act that the human being can do against the environment is still emphasized.
\end{abstract}

Keywords: Constitutional Principiology. Protective state. Safeguard. Rights. Harmful act.

DOI: https://doi.org/10.22478/ufpb.1678-2593.2021v20n44.46055

Conteúdo sob licença Creative Commons: Attribuition-NonCommercial-NoDerivative 4.0 International (CC BY-NC-ND 4.0)

(cc) BY-NC-ND 